\title{
Conteúdo Criativo em Design e Propriedade Intelectual
}

Hugo Backx é Doutor em Design PUC-Rio (2013), Mestre em Engenharia de Produção COPPE/UFRJ (1994), Graduado em Desenho Industrial UFRJ (1986) e Graduado em Direito CUAM (2000). Professor Adjunto - DE no curso de Desenho Industrial - Habilitação Projeto de Produto UFRJ (desde 1986), Advogado OAB/ RJ 111472 (desde 2001). Experiência na área de design de produto, perícia judicial em contrafação de design e Propriedade Intelectual. Coordenador do Laboratório de Propriedade Intelectual - Lapi / UFRJ. Vice-Diretor da Escola de Belas Artes - UFRJ (desde 2018).

$<$ backx@acd.ufrj.br>

ORCID: 0000-0002-3891-9616
Resumo Uma das características das criações intelectuais é o seu caráter imaterial. São conteúdos articulados no plano das ideias de seu criador que livremente constrói e reconstrói um universo imaginário. As motivações vão desde necessidades do dia a dia a alguma manifestação artística. Através de sua exteriorização terceiros tomam ciência do conteúdo criativo por meio de seus contornos ou limites manifestados ou fixados numa espécie de instante "fotográfico" da ideia. Na atividade de design esses conteúdos criativos gerados são fixados em objetos do cotidiano que buscam atender às mais diversas demandas. Essa característica do objeto criativo, fruto do trabalho intelectual, fez surgir a necessidade de normas, como a Propriedade Intelectual, para o seu resguardo. Ela tem como um dos seus princípios básicos a repressão à exploração servil de trabalho criativo alheio. E compreender como o conteúdo criativo em Design se enquadra na Propriedade Intelectual torna este resguardo mais eficaz.

Palavras chave Conteúdo criativo, Design, Propriedade intelectual. 
Madalena Grimaldi é Arquiteta, com Pós-doutorado no Transtechnology Research Group, Plymouth University, Inglaterra, Doutorado em Planejamento Urbano e Regional, Mestrado em Arquitetura. Professora Associada DE do Departamento de Técnicas de Representação Gráfica na EBA, na Universidade Federal do Rio de Janeiro. Tem experiência em Linguagens Técnicas de Representação da Forma e Raciocínio Espacial, atuando nos seguintes temas: Percepção Visual, Metodologias de Ensino, interseções entre arte e matemática, processo criativo, geometria dinâmica e computação gráfica. Lidera o grupo de pesquisa: Percepção Visual e Representação Projetiva. É avaliador e-MEC do Ministério da Educação e atualmente é Diretora da Escola de Belas Artes, UFRJ.

<mgrimaldi@eba.ufrj.brr> ORCID: 0000-0002-9254-1183

\section{Creative Content in Design and Intellectual Property}

Abstract One of the characteristics of creations intellectual is their immaterial character. They are contents articulated in the plane of the ideas of its creator that freely builds and reconstructs an imaginary universe. The motivations range from daily necessities to some artistic manifestation. Through their exteriorization, other people become aware of the creative content through its contours or limits manifested or fixed in a kind of "photographic" moment of the idea. In the design activity, these values-generating contents are fixed in everyday objects that seek to meet the most diverse demands. This characteristic of the creative object, the result of intellectual work, has given rise to the need for norms, such as Intellectual Property, for its protection. It has as one of its basic principles the repression to the slavish exploitation of creative work of others. And understanding how creative content in Design fits into Intellectual Property makes this protection more effective.

Keywords Creative content, Design, Intellectual property. 
Ana Karla possui Pós-Doutorado em Design - UA, Portugal. Doutora em Engenharia de Materiais e de Processos Químicos e Metalúrgicos - PUC Rio. Mestre em Engenharia Agrícola - UFCG PB. Bacharel em Desenho Industrial - UFPB. Professora Adjunta do Curso de Desenho Industrial, Universidade Federal do Rio de Janeiro - UFRJ. Pesquisadora da área de Design \& Materiais e Métodos para seleção de materiais e processos no design. Chair I Congresso Internacional Design \& Materiais 2016. Membro do Comitê Científico do SBDS + ISSD 2017 Simpósio Brasileiro de Design Sustentável + International Symposium on Sustainable Design. Chair. Docente do Programa de Pós-Graduação em Design Visual da Escola de Belas Artes da UFRJ, atuando na Área de Concentração, Design, Tecnologia e Imagem. Coordenadora do Grupo de Pesquisa LED - Laboratório de Experimentações em Design da Escola de Belas Artes, Programa de Pós-Graduação em Design, Universidade Federal do Rio de Janeiro. <anakarla@eba.ufrj.brr> ORCID: 0000-0002-8426-9845

\section{Introdução}

A complexidade dos conteúdos dos objetos criativos em Design e da sistemática de proteção legal das criações intelectuais já indicava a necessidade de uma sistematização que permitisse uma visão dos vínculos que os relacionavam. $O$ trabalho aqui apresentado permite identificar várias interações que ocorrem no sistema através da organização dos conteúdos dispersos em diversos dispositivos legais e material doutrinário, fontes da pesquisa realizada. A estrutura apresentada é a síntese da ponte entre Design e Propriedade Intelectual (PI) que expõe campos de interações com conteúdos diversos em que objetos criativos em Design se revelam multifacetados quando relacionados com a PI. O resultado da criatividade que configura uma obra intelectual é aqui definido como: conteúdo criativo ou objeto criativo.

$\mathrm{O}$ aspecto econômico das criações intelectuais foi um dos fatores que fez surgir a necessidade de instrumentos legais para o seu resguardo, e que têm como função básica a repressão à concorrência desleal originada da exploração servil do trabalho criativo alheio (CERQUEIRA, 2010). Sob este fundamento, legislações foram desenvolvidas visando a proteção e defesa dessas criações intelectuais em diversos campos de atuação humana. Este conjunto de normas compõe a denominada propriedade intelectual (PI).

Os ramos e modalidades da PI que tem relação com os conteúdos criativos em Design são: i) o Direito de Autor na modalidade obra artística; e ii) Propriedade Industrial nas modalidades de invenção, modelo de utilidade, desenho industrial e marcas $^{1}$ (Gráfico 1).

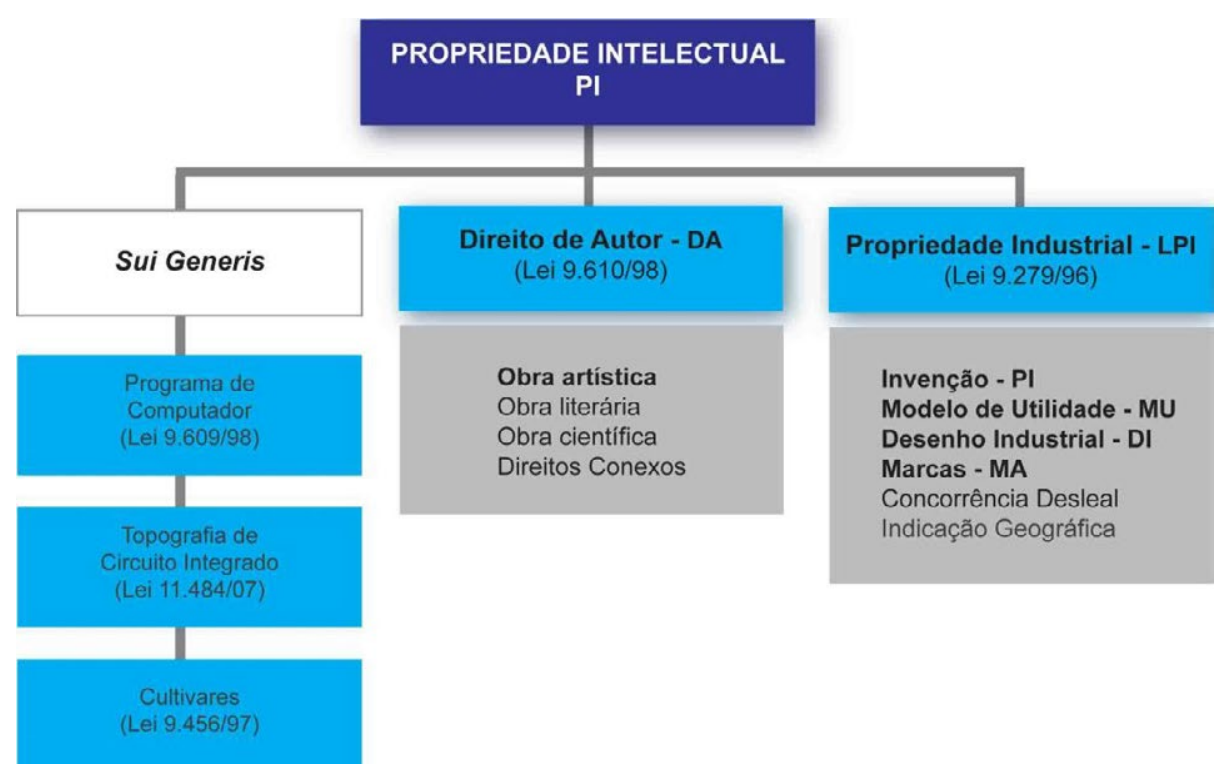

Gráfico 1. Ramos e modalidades da PI

Fonte: do autor 


\section{Conteúdo criativo}

A compreensão de certos conceitos relacionados à criatividade nos permite visualizar melhor a dinâmica da criação. Contudo, criatividade é um processo complexo e um objeto de estudo de limites imprecisos, segundo Martínez:

A criatividade tem sido e é objeto de estudo de muitas disciplinas: da psicologia, da sociologia, da epistemologia, da filosofia, da história, da antropologia, da inteligência artificial, das neurociências e de outras.

Todas elas pesquisam-na baseadas em sua própria especificidade conceitual e metodológica, e muitas das polêmicas atuais derivam não só da complexidade do objeto como tal, mas também da insuficiente precisão dos limites disciplinares e interdisciplinares dentro dos quais a criatividade é abordada.

Na própria psicologia, existem centenas de definições do termo criatividade, em que os autores refletem sua cosmovisão do objeto e/ou os resultados de seus trabalhos dirigidos a responder, de um ponto de vista psicológico, à pergunta: Que é criatividade? (MARTÍNEZ, 2003, p. 9).

Como criatividade não é o objeto central de estudo da presente pesquisa, utilizamos a definição apresentada por Martínez por ser esta de consenso, segundo a autora, entre os estudos já realizados sobre o tema. E, sobretudo, porque aponta um conteúdo de criatividade que nos auxilia entender o processo e ao mesmo tempo relacioná-la ao Design e à propriedade intelectual (PI), por meio do significado de determinadas palavras-chave contidas na própria definição de criatividade apresentada pela autora quando diz que "existe certo consenso em admitir que a criatividade pressupõe uma pessoa que, em determinadas condições e por intermédio de um processo, elabora um produto que é, pelo menos em alguma medida, novo e valioso" (MARTÍNEZ, 2003, p. 9) (Grifos nossos).

As palavras-chave escolhidas do texto são aquelas com algum grau de significação na construção da definição de criatividade e que têm proximidade com as áreas relacionadas: Design e PI. Esta sistemática de recorte visa estabelecer elos entre criatividade, Design e PI a partir de conteúdos que serão associados às palavras-chave. Algumas serão delimitadas a partir de conceitos jurídicos ou econômicos, outros do Design ou da PI. As palavras-chave extraídas ${ }^{2}$ do texto são: pessoa, processo, produto, novo e valioso.

Inicialmente, destacamos o sentido de pessoa, que sob a definição jurídica pode ser natural, física ou jurídica ${ }^{3}$, assim chamada por ser "uma encarnação da lei" (SILVA, 1998, p.609). A distinção entre as definições jurídicas de pessoa é importante em PI porque a atividade intelectual criativa somente se realiza por intermédio de uma pessoa natural ou física e não jurídica, ou seja, esta última não cria a não ser por ação daquela. É a pes- 
soa física quem tem as condições de ser a autora de uma obra criada, pois somente esta tem a capacidade da ação criativa. A pessoa jurídica, porém, pode ser titular de uma obra de uma pessoa natural e dispô-la (licenciar, ceder, doar, etc.). Se a obra é fruto de ações criativas de diversas pessoas físicas então temos múltiplos autores em uma única obra (obra coletiva ${ }^{4}$ ).

A criatividade, por sua vez, realiza-se através de um processo que em design é parte fundamental da atividade de projeto e visa, principalmente, encontrar respostas criativas às demandas postas de modo organizado. Desse processo se obtém como resultado um conteúdo criativo imaterial expresso em um suporte tangível ou intangível ${ }^{5}$ que se traduz em um produto comercial. Este conteúdo imaterial definidor do produto é o objeto de direito que recebe a proteção em PI. Por isso, a aquisição de um determinado objeto criado, via de regra, não torna ninguém proprietário do conteúdo criativo nele contido, pois somente o titular da criação o detém, seja o próprio autor ou outra pessoa. Isto implica limitações legais para replicar o conteúdo fixado na obra sem autorização de seu titular. Por exemplo, ao se adquirir um exemplar de um livro não torna o seu detentor titular do conteúdo criativo ali contido e não o autoriza a replicá-lo indiscriminadamente.

O conceito de novo pode ser entendido no sentido do que não integra o estado da arte ou da técnica ${ }^{6}$. Esta definição de novo afasta as reproduções e imitações que também contêm conteúdos criativos, contudo com um nível de originalidade e novidade comprometido pela igualdade ou similaridade, intencional ou não, com objetos criativos já existentes (estado da técnica). Reproduzir uma criação é diferente de imitá-la. A reprodução equivale a uma cópia do original onde a identidade é em tal nível que até um especialista pode se confundir, ou seja, na reprodução há a certeza da confusão por ser uma "cópia servil, idêntica, sem disfarces" segundo Cerqueira (1982, p. 909). Já a imitação simula o original sem ser uma cópia, gerando um risco de confusão (e não uma certeza) por parte da pessoa pela proximidade com o original diante de certas semelhanças (OLIVEIRA, 2000). Tanto a reprodução quanto a imitação estão expressamente previstas na $\mathrm{LPI}^{7}$.

O Plágio, por sua vez, não tem definição legal no Brasil e nem em legislações internacionais (ABRÃO, 2008), mas apenas doutrinária. Délia Lipsyc o define como uma forma de "apoderamento ideal de todos ou alguns elementos originais contidos na obra de outro autor, apresentando-os como próprio" (LIPSZYC, 1993, p. 567).

O conceito de valioso pode ser entendido sob vários ângulos: simbólico, cultural, social, econômico. Quando o seu sentido é considerado segundo um valor econômico, então este pode ser definido como "o grau de utilidade das coisas, ou bens, ou a importância que lhes concedemos para a satisfação das nossas necessidades" (SILVA, 1998, p.850)

Outro sentido de valioso refere-se à assimetria que há nas relações de troca entre quem vende e quem compra um bem criativo. Esta assimetria de avaliação tende a criar certo desequilíbrio onde um otimismo irracional (irrational optimism) do criador da obra sobre a qualidade de seu trabalho e uma visão estritamente racional do comprador com a sua aversão aos riscos 
em face de um objeto criativo emocionalmente avaliado e a possibilidade de arrependimento. Essas posições antagônicas de valoração de objetos criativos acabam por gerar o chamado "efeito da criatividade" (creativity effect) no mercado de bens intelectuais (SPRIGMAN \& BUCCAFUSCO, 2011).

São noções de valor que, sob o aspecto econômico, têm um viés importante nas discussões e fundamentos para o resguardo legal das criações intelectuais em PI. Entretanto, certas práticas buscam a sua mitigação sob o fundamento do fim social de toda propriedade, inclusive a intelectual. Nesse sentido, já há ações práticas que dão conta de dispor o uso livre da criação quando é sem fins lucrativos, por meio de licenças com alguns direitos reservados: Creative Commons.

Ainda sob o viés social de valioso, temos o reconhecimento diferenciado dos conteúdos criativos geradores de soluções não óbvias de determinadas demandas que não foram respondidas por quem tinha o domínio na área e não foi capaz de solucioná-las. Assim, esta capacidade criativa distinta tem valor socialmente reconhecido:

(...) quando há sinais de que a solução de um problema não era óbvia porque aqueles com conhecimento na área estavam céticos sobre esta possibilidade ou havia uma necessidade há muito sentida demandando uma solução, a sociedade valoriza a criatividade que a solucionou (FROMER, 2016, p. 1488) (tradução nossa) ${ }^{8}$

Com as definições das palavras-chave postas, o conceito de criatividade de Martínez (2003) pode ser assim reconstruído com vista a associar o Design e a PI em um núcleo comum: o designer enquanto pessoa natural realiza um produto expresso em um suporte [tangível ou intangível], com conteúdo criativo novo [distinto do estado da técnica] e valioso [valor econômico e/ou social], através de determinadas condições e processo [processo sistematizado].

Essas seriam então as condições básicas para que o resultado da atividade de design possa se vincular à propriedade intelectual tendo em vista o núcleo comum entre ambos: conteúdo criativo. Sendo este o objeto passível de proteção daquele. 


\section{Atributos estéticos e técnicos dos conteúdos criativos em PI}

Além das características criativas e imaterial dos conteúdos em design também há dois atributos do objeto importantes que se relacionam com a PI: o estético e o técnico ${ }^{9}$. A cisão entre ambos na PI é assim tratada por Newton Silveira (1996):

(...) a criatividade do homem se exerce ora no campo da técnica, ora no campo da estética. Em consequência, a proteção jurídica ao fruto dessa criatividade também se dividiu em duas áreas: a criação estética é objeto do direito de autor; a invenção técnica, da propriedade industrial (SILVEIRA, 1996, p.5) (Grifos nossos).

A criação intelectual humana é complexa e muitas vezes a identificação dos conteúdos criativos a partir unicamente de atributos estéticos e técnicos não se mostra simples. Esta separação tem caráter sistêmico de cunho prático, pois a realidade desses se revela entrelaçada como um todo integrado onde nem sempre as fronteiras são claramente identificadas. São conteúdos criativos que podem se revelar múltiplos em suas funções. Por exemplo, em objetos criativos de tempos remotos em que se supunha deveriam privilegiar essencialmente uma economia de subsistência (função técnica), não se revelaram assim. São objetos com uma polaridade entre o técnico e o estético associado ao simbólico para além da simples resposta direta às necessidades práticas de seus usuários:

Não é preciso ser antropólogo ou especialista. Um simples passeio pelos museus de etnografia nos ensina serem as ferramentas indígenas - cuias, arcos, flechas, bordunas, remos, canoas, potes, cestos, etc. - muito mais que objetos técnicos e funcionais capazes apenas de cumprir as tarefas que deles se esperam: são também objetos estéticos, dedicados à contemplação e ao manuseio prazeroso, à veiculação de mensagens míticas e rituais. Estes instrumentos contêm um excesso simbólico, um algo mais, incompatível com seres para os quais o estômago seja mais urgente que o intelecto ou a sensibilidade. (RODRIGUES, 1989, p. 85-6).

Portanto, apesar do atributo simbólico poder compor um determinado objeto, para a PI é necessário que o conteúdo criativo resultado da dinâmica projetiva seja identificado apenas segundo os critérios de atributos estéticos e técnicos do objeto. Alguns apresentam ambos os atributos constitutivos em um único objeto (híbrido), importando em vários enquadramentos. A partir desses o conteúdo criativo do objeto poderá ser enquadrado em um dos dois ramos de proteção e defesa: direito autoral (DA) ou propriedade industrial (LPI).

Além disso, o design tem a característica de atividade múltipla por englobar diversos campos de atuação e de gerar conteúdos criativos variados onde cada campo de atuação demanda conhecimentos específicos que o distingue dos demais (Figura 1). 


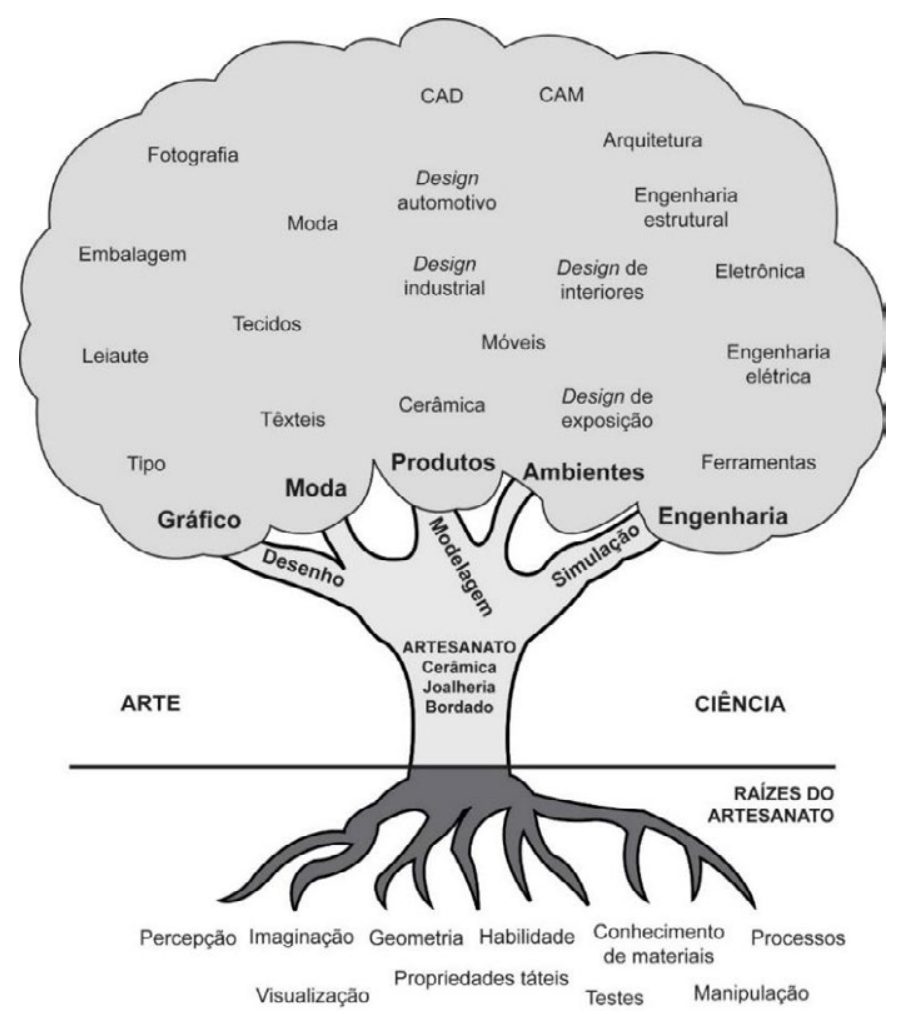

Fig 1. Conteúdos do Design.

Fonte: adaptado de Walker (1995)

Apesar dessa variedade de conteúdos no Design em relação à PI o que predomina são, principalmente, os atributos estéticos e técnicos das criações intelectuais. Além deles também são considerados para determinadas modalidades de proteção se o objeto criativo é bi ou tridimensional ou a característica da sua configuração espacial (conjunto-imagem)

Os atributos estéticos e técnicos, assim como os aspectos bi ou tridimensionais do objeto criativo estão definidos nas modalidades de proteção (LPI: invenção, modelo de utilidade, desenho industrial, marcas, DA: obra artística) e são delimitados nos dispositivos normativos correspondentes.

Já a configuração espacial com característica particular distintiva em relação a outras do mesmo ramo de negócio abrangem o denominado conjunto-imagem ou trade dress. Este não se vincula a qualquer aspecto específico bi ou tridimensional, assim como estético ou técnico do objeto para a sua configuração, bastando ter alguma característica criativa particular de conjunto (Figura 2). Esta característica não tem uma modalidade específica de proteção na PI, sendo utilizado como dispositivo de defesa com vista à repressão à concorrência desleal, esta sim, tipificada na LPI (Gráfico 1).

A Figura 2 exemplifica um produto hipotético com vários conteúdos criativos de design e apresenta a vinculação de cada elemento criativo a um dos ramos da PI (DA ou LPI). Também sinaliza o conjunto-imagem (trade dress) dos elementos gráficos (fotografia ou desenho e marca registrada) 


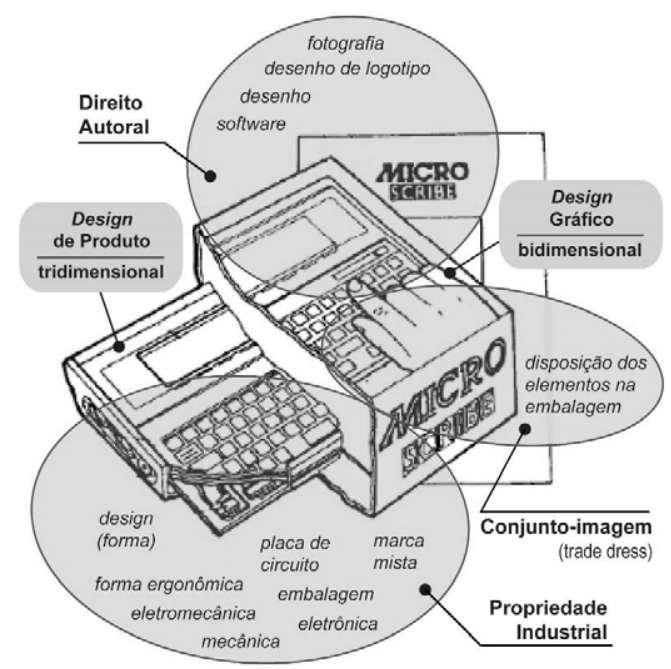

Fig 2. Ramos de proteção de um produto hipotético. Fonte: adaptado de PUGH (1990) dispostos de modo particular na embalagem do produto final, desde que como elemento distintivo próprio (conjunto-imagem) em relação ao seu segmento de atuação.

Saber se determinado conteúdo criativo se vincula a certa modalidade em LPI ou DA mostra-se uma tarefa que requer conhecimento. $O$ sistema legal de proteção e defesa das criações intelectuais apresenta-se atualmente em diversas normas legais sem uma codificação única e integrada, podendo deixar aqueles que não são especialistas na área, confusos, seja em razão do linguajar jurídico ou da pouca integração das legislações.

Embora as áreas de atuação do designer sejam diversificadas, o resultado de seu trabalho intelectual pode se relacionar com seguintes ramos da PI: DA ou LPI. Em alguns casos pode vir a estar sob o amparo de ambos. Por exemplo, em uma coleção de roupas em que há aplicação de estampas, o conteúdo expressivo do desenho (elemento estético) será protegido pelo DA, enquanto a sua aplicação industrial pode ser pela LPI (desenho Industrial). Havendo inovação sob o aspecto técnico, pode ser solicitada a proteção via modelo de utilidade ou invenção.

O desenho como módulo padrão da estampa abaixo (Figura 3) está protegido pelo DA como obra artística, pois esta proteção independe de qualquer solicitação. Já o desenho como padrão que será utilizado como tipo industrial, aplicação não alcançada pelo DA, foi resguardado como Desenho Industrial junto ao INPI ${ }^{10}$ (Quadro 1).

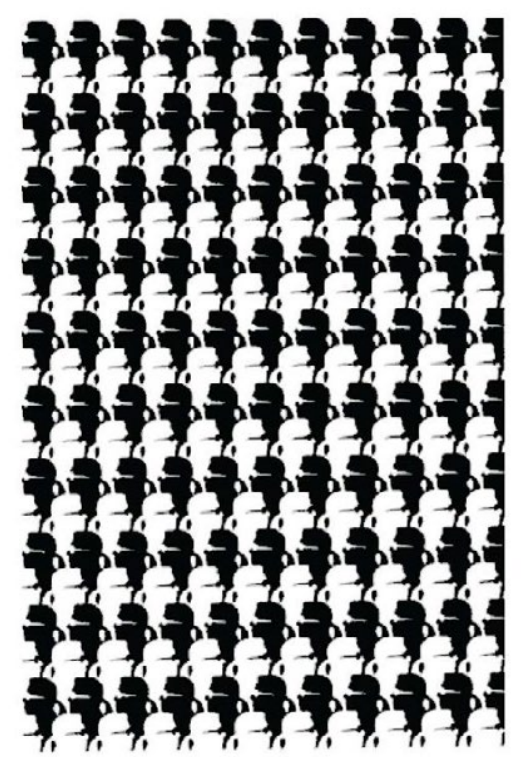

Padrão ornamental aplicado em estampa Karl Lagerfeld B. V. / Trey Laird e Melina Kok DI7105744-7, RPI2160, p. 241

Fig 3. Estampa.

Fonte: adaptado da RPI 2160 (patentes)

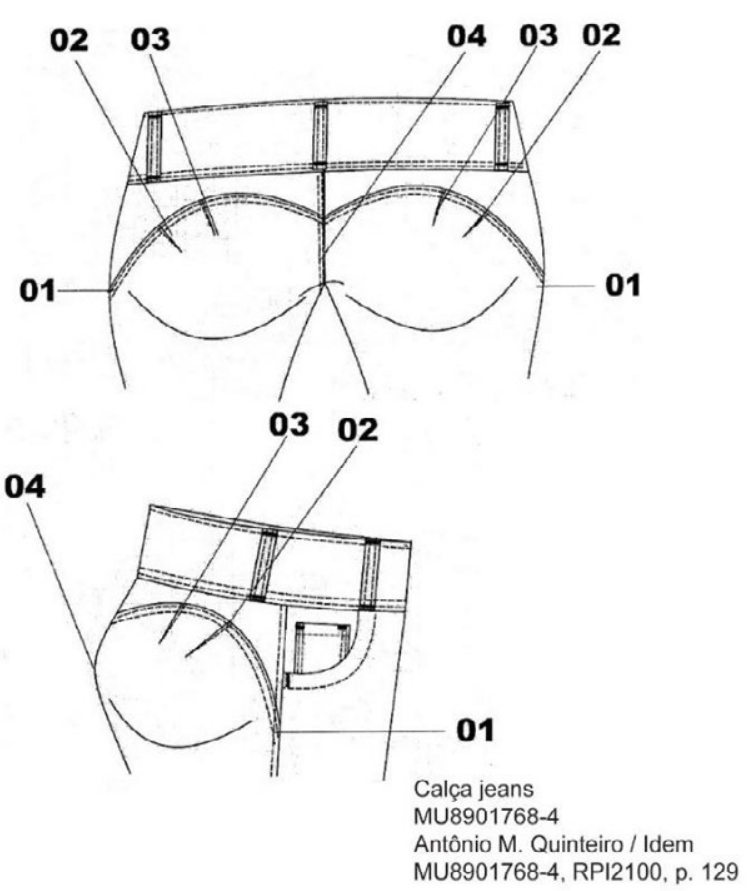

Fig 4. Calça jeans.

Fonte: adaptado da RPI 2100 (patentes)

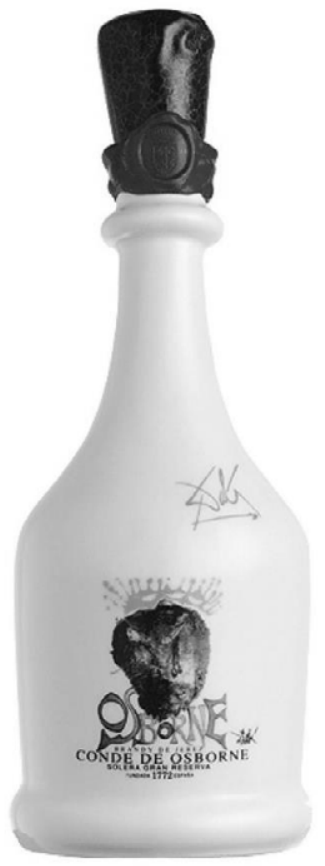

Imagem 1. Garrafa Conde de Osborne. Fonte: adaptado do site www. osborne-shop.com ${ }^{12}$ 
Outro exemplo, agora com conteúdo criativo técnico, é de um jeans com pedido de proteção como modelo de utilidade junto ao INPI (Figura 4).

Algumas vezes um único objeto apresenta conteúdos criativos diversos, podendo demandar proteções distintas segundo esses conteúdos. A forma plástica definidora do limite externo do objeto criado tem esta característica de apresentar esta possibilidade de acúmulo de conteúdos criativos em um mesmo objeto (Imagem 1). Lastres (2008) assim ponderou a respeito:

\footnotetext{
(...) ao pensar na famosa garrafa criada por Salvador Dalí para a marca de brandy "Conde de Osborne" ninguém contesta que é uma obra de arte aplicada à indústria, mas também é indiscutível que pode originar um desenho industrial e até mesmo uma marca tridimensional (...). A natureza híbrida do design, que se situa entre a propriedade industrial e os direitos autorais, requer a difícil tarefa de identificar não apenas as características específicas de cada uma das figuras em que uma única e mesma criação pode dar origem, mas também as áreas comuns que podem ser compartilhadas (LASTRES, 2008, p. 218) (Tradução nossa) ${ }^{11}$.
}

O objeto criativo protegível apresenta conteúdo que o relaciona com uma determinada modalidade seja no DA ou LPI, este, por sua vez, estabelece os requisitos que aquele deve atender para o seu enquadramento. Contudo, são requisitos descritos em diversos dispositivos normativos que impõe o seu conhecimento pleno para a adequada identificação do conteúdo criativo e sua vinculação com a respectiva modalidade.

É o caso do exemplo da garrafa anteriormente dado, quando se diz que esta pode ser uma marca tridimensional e desenho industrial ao mesmo tempo. Como marca porque atende o requisito de distintividade e tridimensionalidade e como Desenho Industrial pela forma plástica original resultante e do conteúdo estético do objeto que atende a ambas as modalidades.

Síntese

A pesquisa aqui apresentada expôs em linhas gerais como os conteúdos criativos em Design se vinculam à PI, sejam através dos atributos estéticos ou técnicos ou de ambos, ou de suas características bi ou tridimensionais, além dos objetos criativos que envolvem conjunto (conjuntoimagem ou trade dress) sem possibilidade de enquadramento em uma das modalidades específicas de proteção apresentadas a seguir.

No Quadro 1 o atributo estético não fica restrito unicamente ao direito de autor (DA), como sugere Silveira (1996), porque no DA o caráter industrial ou comercial de um conteúdo criativo não é amparado. Portanto, obras com este caráter e atributo estético devem ser protegidas pela LPI seja como marca ou desenho industrial (forma gráfica ou plástica). 0 atributo técnico, contudo, fica restrito unicamente à invenção e ao modelo de utilidade. As obras artísticas podem ser registradas na Escola de Belas Artes (EBA) e as marcas, desenho industrial, modelo de utilidade e invenção no 
Instituto Nacional de Propriedade Industrial (INPI). As marcas e o desenho industrial por terem conteúdo criativo estético e ao mesmo tempo aplicação industrial ou comercial ocupam uma área intermediária entre a artística e a industrial.

Quadro 1. Mapa síntese.

Fonte: do autor

\begin{tabular}{|c|c|c|c|c|c|c|}
\hline \multicolumn{7}{|c|}{ TIPIFICAÇÃO DOS CONTEÚDOS CRIATIVOS EM PI } \\
\hline LEI & $\begin{array}{l}\text { Atributo I } \\
\text { Conteúdo }\end{array}$ & CARACTERISTICA & OBSERVAÇĀo & MODALIDADE & & ÁREA \\
\hline$\varangle$ & 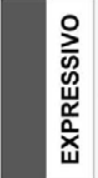 & Artistico & $\begin{array}{l}\text { Dissociado do caráter } \\
\text { industrial ou comercial } \\
\text { Tipos: } \\
\text { Desenho, figuras, esculturas, } \\
\text { personagens, pinturas, etc. }\end{array}$ & Obra Artistica & 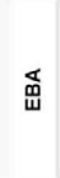 & $\begin{array}{l}\frac{\pi}{O} \\
\frac{E}{0} \\
\frac{O}{6} \\
\frac{\alpha}{\alpha}\end{array}$ \\
\hline \multirow{4}{*}{$\bar{a}$} & 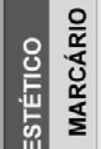 & Sinal distintivo & $\begin{array}{l}\text { Visualmente perceptivel } \\
\text { Tipos: } \\
\text { Marca Mista, Figurativa e } \\
\text { Tridimensional }\end{array}$ & Marca - MA & & $\frac{\overleftarrow{\alpha}}{\underline{\alpha}}$ \\
\hline & $\frac{\overrightarrow{\underline{\alpha}}}{\underline{\alpha}}$ & Aplicação industrial & $\begin{array}{l}\text { Tipos: } \\
\text { Conjunto ornamental de linhas } \\
\text { e cores aplicáveis em produto } \\
\text { [bidimensional] } \\
\text { Forma plástica ornamental de } \\
\text { um objeto [tridimensional] }\end{array}$ & $\begin{array}{l}\text { Desenho } \\
\text { Industrial - DI }\end{array}$ & $\underline{\bar{a}}$ & 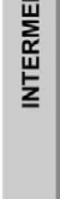 \\
\hline & \multirow{2}{*}{ 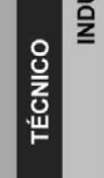 } & Aplicação industrial & $\begin{array}{l}\text { Objeto de uso prático, ou parte } \\
\text { deste, com nova forma ou } \\
\text { disposição. }\end{array}$ & $\begin{array}{l}\text { Modelo de } \\
\text { Utilidade - MU }\end{array}$ & & \multirow{2}{*}{ 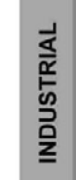 } \\
\hline & & Aplicação industrial & $\begin{array}{l}\text { Objeto ou parte deste } \\
\text { Processo }\end{array}$ & Invenção - PI & & \\
\hline
\end{tabular}

\section{Conclusão}

Saber os alcances de um determinado conteúdo criativo e se este se vincula a certa modalidade da PI é uma tarefa que requer conhecimento do sistema normativo de proteção das criações intelectuais. É um sistema que se apresenta atualmente de modo disperso em diversas leis e normas sem uma codificação única e integrada, deixando aqueles que não são conhecedores da área, confusos, seja em razão do linguajar jurídico ou em razão da pouca integração desses institutos.

O núcleo criativo da atividade em design definitivamente sela o seu vínculo com a PI, seja antes, durante ou depois de qualquer ação criativa. $\mathrm{E}$ com o conhecimento de PI pode-se reduzir as chances do designer no processo criativo de ultrapassar a linha que separa uma obra original de uma imitação ou plágio de um trabalho alheio. São fronteiras que muitas vezes se apresentam tênues e que podem se sobrepor à propriedade imaterial de terceiros. É um conhecimento que ajuda não só a resguardar as criações intelectuais próprias, mas também àqueles de boa-fé que as criam a não ultrapassarem tais fronteiras. 
1 A concorrência desleal é uma modalidade da LPI que também pode resguardar algumas criações de design, contudo, apenas no âmbito das defesas em juízo.

2 A palavra "condições" não foi utilizada por não ter sido possível relacioná-la ao Design e PI.

3 Título I e Il, do Livro I - Parte Geral, do Código Civil.

4 Obra coletiva: letra "h", do inciso 80, do art. 50, da Lei Autoral.

h) coletiva - a criada por iniciativa, organização e responsabilidade de uma pessoa física ou jurídica, que a publica sob seu nome ou marca e que é constituída pela participação de diferentes autores, cujas contribuições se fundem numa criação autônoma.

5 Suporte da obra intelectual: art. 70 e incisos, da Lei Autoral.

Art. 70 São obras intelectuais protegidas as criações do espírito, expressas por qualquer meio ou fixadas em qualquer suporte, tangível ou intangível, conhecido ou que se invente no futuro, tais como: (...).

6 Estado da técnica: '§ 100 estado da técnica é constituído por tudo aquilo tornado acessível ao público antes da data de depósito do pedido de patente, por descrição escrita ou oral, por uso ou qualquer outro meio, no Brasil ou no exterior, ressalvado o disposto nos arts. 12, 16 e 17". (§10, do art. 11, da LPI).

7 Art. 124, inciso XIX, e art. 187

8 (...) when there are signs that a problem solution was not obvious because those with prior knowledge in the art were skeptical about the possibility of the solution or there had been a long-felt need for the solution, society values the creativity that produced the solution.

9 Embora o atributo simbólico seja significativo para o design, não é aqui considerado porque não estabelece uma vinculação direta com a PI. 10 Instituto Nacional de Propriedade Industrial - INPI

11 (...) piénsese en la conocida botella que creó Salvador Dalí para el brandy de la marca "Conde de Osborne": nadie discute que se trata de una obra de arte aplicado a la industria, pero también es indiscutible que puede originar un diseño industrial y hasta una marca tridimensional (...). La naturaleza híbrida del diseño, que está situado entre la propiedad industrial y el derecho de autor, exige la difícil tarea de perfilar no solo los rasgos específicos de cada una las figuras a que puede dar lugar una única y misma creación de forma, sino también las zonas comunes que pueden llegar a compartir.

12 https://www.osborne-shop.com/liquors/conde-de-osborne-dali-edition. Acesso em 01 dez 2017.

\section{Referências}

ABRÃO, Eliane Y. Titularidade e liberdade no uso de ideias e formatos na propriedade intelectual. In: ADOLFO, Luiz G. S.; MORAES, Rodrigo. Propriedade Intelectual em perspectiva. Rio de Janeiro: Editora Lúmen Juris, 2008.

BRASIL. Direito autoral - Lei no 9.610, de 19/02/98.

BRASIL. Lei de propriedade industrial - Lei no 9.279, de 14/05/96.

CERQUEIRA, João da Gama. Tratado da Propriedade Industrial: da propriedade industrial e do objeto dos direitos. Atualizado por: Newton Silveira e Denis B. Barbosa. Rio de Janeiro: Lumen Juris, vol. I, 2010.

CERQUEIRA, João da Gama. Tratado da Propriedade Industrial. 2a ed. São Paulo: Revista dos Tribunais - RT, Vol. 2, 1982. 
FROMER, Jeanne C. A psychology of intellectual property. Northwestern University Law Review, vol. 104, p. 1441-1510, 2010. Disponível em: http://ssrn.com/abstract=1575843. Acesso em: 08 mar 2016 .

LASTRES, José Manuel Otero. Reflexiones sobre el diseño industrial. In: Anuario de la Facultad de Derecho: Universidad de Alcalá, no 1, 2008, pp. 217-235. Disponível em: http://dspace.uah. es/ jspui/bitstream/10017/6417/1/reflexiones_ote-ro_AFDUA_2008.pdf. Acesso: 16 out 2011. LIPSZYC, Délia. Derecho de autor y derechos conexos. Buenos Aires: UNESCO/Cerlac/Zavalia, 1993.

MARTíNEZ, A. M. Criatividade, personalidade e educação. 3a edição. Trad. Mayra Pinto. São Paulo: Papirus, 2003.

OLIVEIRA, Maurício L. Propriedade Industrial: 0 âmbito de proteção à marca registrada. Rio de Janeiro: Editora Lumen Juris, 2000.

PUGH, S. Total Design: integrated methods for successful product engineering. 3a ed. Inglaterra: Addilson-Wesley, 1990.

REVISTA DE PROPRIEDADE INDUSTRIAL. Patentes. RPI no 2110. Rio de Janeiro: INPI, p. 129. . Patentes. RPI no 2160. Rio de Janeiro: INPI, p. 241.

RODRIGUES, José Carlos. Antropologia e Comunicação: princípios radicais. Rio de Janeiro: Editora PUC-Rio, coleção Ciências Sociais no 5, 1989, e-book. Disponível em: http://www. editora.vrc.puc-rio/docs/ebook_antropologia_comunicação.pdf. Acesso em: 09 dez 2011. SILVA, De Plácido. Vocabulário Jurídico. 15a edição. Rio de Janeiro: Forense, 1998.

SILVEIRA, Newton. A Propriedade Intelectual e a nova Lei de Propriedade Industrial (Lei no 9.279, de 14-05-1996). São Paulo: Saraiva, 1996.

SPRIGMAN, Christopher \& BUCCAFUSCO, Christopher. The criativity effect. University of Chicago Law Review, Volume 78, Number 1, 2011. Disponível em: http://works.bepress.com/ sprigman/8. Acesso em: 08 mar 2012.

WALKER, David et al. Managing Design: Overview Issues. P791. Open University Press, Milton Keynes, p. 22. In: COOPER, Rachel; PRESS, Mike. The Design Agenda: a guide to successful design management. England: John Wiley \& Sons, 1995, Cap. II, p. 27 